\title{
High-Flow Oxygen Therapy: Pressure Analysis in a Pediatric Airway Model
}

\author{
Javier Urbano MD, Jimena del Castillo MD, Jesús López-Herce MD PhD, José A Gallardo MD, \\ María J Solana MD, and Ángel Carrillo MD PhD
}

\begin{abstract}
BACKGROUND: The mechanism of high-flow oxygen therapy and the pressures reached in the airway have not been defined. We hypothesized that the flow would generate a low continuous positive pressure, and that elevated flow rates in this model could produce moderate pressures. The objective of this study was to analyze the pressure generated by a high-flow oxygen therapy system in an experimental model of the pediatric airway. METHODS: An experimental in vitro study was performed. A high-flow oxygen therapy system was connected to 3 types of interface (nasal cannulae, nasal mask, and oronasal mask) and applied to 2 types of pediatric manikin (infant and neonatal). The pressures generated in the circuit, in the airway, and in the pharynx were measured at different flow rates $(5,10,15$, and $20 \mathrm{~L} / \mathrm{min})$. The experiment was conducted with and without a leak (mouth sealed and unsealed). Linear regression analyses were performed for each set of measurements. RESULTS: The pressures generated with the different interfaces were very similar. The maximum pressure recorded was $4 \mathrm{~cm} \mathrm{H}_{2} \mathrm{O}$ with a flow of $20 \mathrm{~L} / \mathrm{min}$ via nasal cannulae or nasal mask. When the mouth of the manikin was held open, the pressures reached in the airway and pharynxes were undetectable. Linear regression analyses showed a similar linear relationship between flow and pressures measured in the pharynx (pressure $=-0.375+0.138 \times$ flow) and in the airway (pressure $=-\mathbf{0 . 3 7 5}+\mathbf{0 . 1 5 8} \times$ flow) with the closed mouth condition. CONCLUSIONS: According to our hypothesis, high-flow oxygen therapy systems produced a low-level CPAP in an experimental pediatric model, even with the use of very high flow rates. Linear regression analyses showed similar linear relationships between flow and pressures measured in the pharynx and in the airway. This finding suggests that, at least in part, the effects may be due to other mechanisms. Key words: high-flow oxygen therapy; nasal cannulae; continuous positive airway pressure; pediatrics; respiratory support. [Respir Care 2012;57(5):721-726. (C) 2012 Daedalus Enterprises]
\end{abstract}

\section{Introduction}

There is a need for oxygen therapies between invasive mechanical ventilation on one extreme and standard oxygen therapy on the other. Actually, 2 systems are available

\footnotetext{
The authors are affiliated with the Pediatric Intensive Care Department, Hospital General Universitario Gregorio Marañón, Complutense University of Madrid, Madrid, Spain.
}

The authors have disclosed no conflicts of interest.

Correspondence: Jesus Lopez-Herce MD PhD, Pediatric Intensive Care Department Hospital General Universitario Gregorio Marañón, Complutense University of Madrid, Calle de Doctor Castelo 47, 28009 Madrid, Spain. E-mail: pielvi@ hotmail.com.

DOI: $10.4187 /$ respcare. 01386 in the pediatric population: noninvasive ventilation (NIV) and high-flow oxygen therapy. NIV is an ever more widely used method of ventilation, both for the management of moderate respiratory failure and for the withdrawal of invasive mechanical ventilation. ${ }^{1,2}$ However, adaptation to NIV can be complicated in some children, particularly in infants, and NIV can cause skin lesions when applied through nasal or oronasal mask, due to the pressure of the mask. ${ }^{3}$ Nasal prongs are commonly used in newborns and small infants, who often develop lesions in the nasal mucosa and septum. ${ }^{4}$ Recently, high-flow oxygen therapy systems have been designed that can administer mixtures of warm, humidified gas at flow rates between 6 and $50 \mathrm{~L} /$ min via nasal cannulae or prongs. ${ }^{5}$ These systems are well tolerated, easy to use, and can be effective in patients with elevated oxygen requirements and/or moderate respiratory failure, although there is still little experience with their 


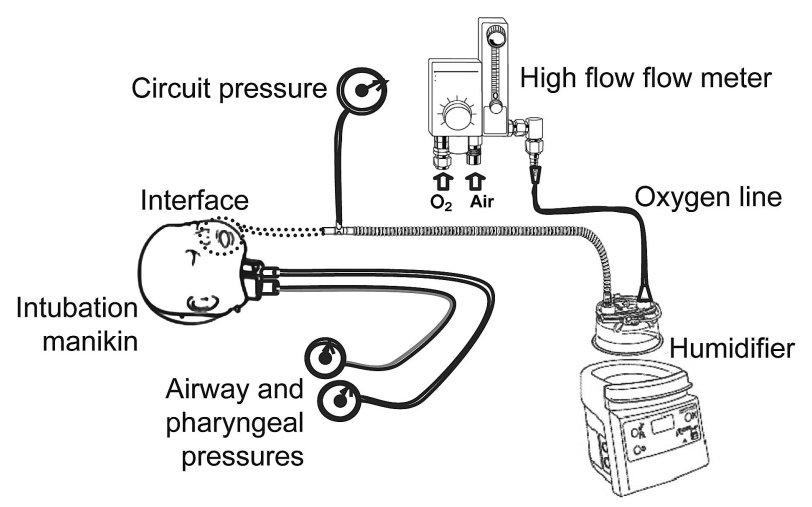

Fig. 1. Diagram of the system setup for evaluating the pressure generated with high-flow oxygen therapy.

use in neonates and children. ${ }^{6-11}$ The mechanism through which high-flow oxygen therapy works is not fully understood. It may be that the beneficial effect is due only to an increase in the flow, or because this produces a small, continuous distending pressure in the airway (CPAP). ${ }^{12-14}$ Although some studies have attempted to measure the CPAP produced by high-flow oxygen therapy in neonates, $7,15,16$ there are few studies that have investigated the mechanism of action of this technique in children or the pressures generated. ${ }^{17-19}$

The objective of the present study was to investigate the pressure generated by a high-flow oxygen therapy system in an experimental pediatric airway model. We hypothesize that flow would generate continuous positive pressure when leak between the interface and the patient is low, and that elevated flow rates in this model could produce moderate pressures.

\section{Methods}

The experiments were performed using a high-flow oxygen therapy system connected to 3 types of interface that were applied to 2 pediatric manikins (Fig. 1). A high-flow system was used that functioned with a mixture of gases (Bird, Viasys Healthcare, Palm Springs, California), with a flow meter for high flow rates (Medimeter, Mediline GCE Group, Chotěbŏr, Czech Republic) able to deliver flows between 0 and $30 \mathrm{~L} / \mathrm{min}$, and a heated respiratory humidifier (MR410, Fisher \& Paykel Healthcare, Auckland, New Zealand), connected to the different interfaces via a $100 \mathrm{~cm}$ length of $1.5 \mathrm{~cm}$ diameter corrugated tube (Intersurgical, Wokingham, United Kingdom) (see Fig. 1).

Three types of interface were used: pediatric nasal cannulae (Vapotherm, Stevensville, Maryland) of $0.2 \mathrm{~cm}$ external diameter; silicone nasal mask (Sullivan Infant Bubble Mask, ResMed, North Ryde, Australia); and oronasal mask (Profile Lite, Philips Respironics, Murrysville, Pennsylvania). The interfaces were applied to an infant manikin

\section{QUICK LOOK}

\section{Current knowledge}

High-flow oxygen via nasal cannula improves oxygenation in infants, through a variety of mechanisms.

\section{What this paper contributes to our knowledge}

High-flow oxygen (up to $20 \mathrm{~L} / \mathrm{min}$ ) via nasal cannulae, nasal mask, or oronasal mask generated low CPAP levels in 2 models of the upper way of an infant and a newborn. Patients' improvement with high-flow oxygen may involve mechanisms other than positive pressure.

(ALS Baby, Laerdal Medical, Stavanger, Norway) and to a neonatal endotracheal intubation manikin (Newborn Baby Intubation Training Model 250-00101, Laerdal Medical, Stavanger, Norway). The nares of the manikins had diameters of $6 \mathrm{~mm}$ (ALS Baby) and $4 \mathrm{~mm}$ (Newborn Baby Intubation) and permitted the interposition of systems to measure pressures in the airway and pharynx of the manikin.

The pressures were measured using a manometer (Portex 0473, Smiths Medical, Watford, United Kingdom) that records pressures between 0 and $120 \mathrm{~cm} \mathrm{H}_{2} \mathrm{O}$, with measurements taken at 3 points: in the most distal part of the respiratory circuit (circuit), close to the connection with the interface; in the distal part of the airway of the manikin (airway); and in the tube corresponding to the hypopharynx-digestive tract of the manikin (pharynx) (see Fig. 1). The model was validated by the application of increasing amounts of CPAP through nasopharyngeal prongs by a noninvasive ventilator in both manikins. We observed that pressures measured with the manometer in the circuit agreed with the pressures measured by the ventilator; and that pressures measured by the manometers placed in the theoretical airway and pharynx of the manikins correlated adequately with the CPAP administered. Linear regression showed an $\mathrm{r}^{2}=0.97$ (measured pressure $=1.7+$ $0.469 \times$ programmed pressure).

Measurements were performed in both manikins with all 3 interfaces. After installing the pressure measurement system at the desired site, the interface was positioned on the face of the manikin, as would be done in clinical practice. The measurements were initially performed with the mouth of the manikin open, and were then repeated with the mouth sealed with tape to simulate a patient with the mouth closed. The absence of leak was verified by auscultation and by touch, as we usually do in clinical practice. The mouth was not sealed when oronasal mask was used. After allowing the system to stabilize for $30 \mathrm{sec}-$ onds, the pressures reached with increasing flows of 5,10 , 15 , and $20 \mathrm{~L} / \mathrm{min}$ were recorded, collected, and analyzed 
High-Flow Oxygen Therapy: Pressure Analysis in a Pediatric Airway Model

Table 1. Circuit, Airway, and Pharyngeal Pressures Generated in the Infant Manikin

\begin{tabular}{|c|c|c|c|c|c|c|c|}
\hline & \multirow{3}{*}{ Flow, L/min } & \multicolumn{6}{|c|}{ Pressure, $\mathrm{cm} \mathrm{H}_{2} \mathrm{O}$} \\
\hline & & \multicolumn{2}{|c|}{ Circuit } & \multicolumn{2}{|c|}{ Pharynx } & \multicolumn{2}{|c|}{ Airway } \\
\hline & & Mouth Open & Mouth Closed & Mouth Open & Mouth Closed & Mouth Open & Mouth Closed \\
\hline \multirow[t]{4}{*}{ Cannulae } & 5 & 45 & 55 & 0 & 0 & 0 & 1 \\
\hline & 10 & 95 & 110 & 0 & 1 & 0 & 1.5 \\
\hline & 15 & $>120$ & $>120$ & 0 & 1.5 & 0 & 2.5 \\
\hline & 20 & $>120$ & $>120$ & 0.5 & 2.5 & 0.5 & 4 \\
\hline \multirow[t]{4}{*}{ Nasal mask } & 5 & 0.5 & 1.5 & 0 & 1 & 0 & 1 \\
\hline & 10 & 1.5 & 2 & 0 & 1.5 & 0 & 1.5 \\
\hline & 15 & 2 & 3.5 & 0 & 2 & 0 & 2 \\
\hline & 20 & 3.5 & 5 & 0 & 2.5 & 0 & 3.5 \\
\hline \multirow[t]{4}{*}{ Oronasal mask } & 5 & ND & 0.5 & ND & 0.5 & ND & 0 \\
\hline & 10 & ND & 1.5 & ND & 1.5 & ND & 1 \\
\hline & 15 & ND & 2.5 & ND & 2.5 & ND & 1.5 \\
\hline & 20 & ND & 4 & ND & 3 & ND & 3 \\
\hline
\end{tabular}

Table 2. Circuit, Airway, and Pharyngeal Pressures Generated in the Newborn Manikin

\begin{tabular}{|c|c|c|c|c|c|c|c|}
\hline & \multirow{3}{*}{ Flow, L/min } & \multicolumn{6}{|c|}{ Pressure, $\mathrm{cm} \mathrm{H}_{2} \mathrm{O}$} \\
\hline & & \multicolumn{2}{|c|}{ Circuit } & \multicolumn{2}{|c|}{ Pharynx } & \multicolumn{2}{|c|}{ Airway } \\
\hline & & Mouth Open & Mouth Closed & Mouth Open & Mouth Closed & Mouth Open & Mouth Closed \\
\hline \multirow[t]{4}{*}{ Cannulae } & 5 & 45 & 50 & 0 & 0 & 0 & 0 \\
\hline & 10 & 95 & 95 & 0 & 0.5 & 0 & 0.5 \\
\hline & 15 & $>120$ & $>120$ & 0 & 1 & 0 & 1 \\
\hline & 20 & $>120$ & $>120$ & 0 & 1.5 & 0 & 1.5 \\
\hline \multirow[t]{4}{*}{ Nasal mask } & 5 & 0 & 0 & 0 & 0 & 0 & 1 \\
\hline & 10 & 0 & 1.5 & 0 & 1 & 0 & 1.5 \\
\hline & 15 & 0 & 2 & 0 & 2 & 0 & 2.5 \\
\hline & 20 & 1 & 3 & 0 & 3 & 0 & 3.5 \\
\hline \multirow[t]{4}{*}{ Oronasal mask } & 5 & ND & 0 & ND & 0.5 & ND & 0.5 \\
\hline & 10 & ND & 1 & ND & 0.5 & ND & 0.5 \\
\hline & 15 & ND & 2 & ND & 1 & ND & 1 \\
\hline & 20 & ND & 3 & ND & 2 & ND & 2.5 \\
\hline
\end{tabular}

using database software (SPSS, Chicago, Illinois). Each measurement was taken twice, and the mean was reported. Linear regression analyses were performed for each set of measurements.

\section{Results}

The results are presented in Tables 1 and 2. In both manikins, the pressures reached in the airway and pharynx were undetectable when the mouth was open, independent of the interface used. The pressures in the circuit were high when nasal cannulae were used, and were related to the flow; with the other 2 interfaces the circuit pressures were practically undetectable.

When the mouth was closed, there was a flow-related increase in the pressures reached (see Tables 1 and 2 and Fig. 2). In the ALS Baby manikin the pressures generated with the different interfaces were very similar, both in the airway and in the pharynx; the maximum pressure recorded was $4 \mathrm{~cm} \mathrm{H}_{2} \mathrm{O}$ with a flow of $20 \mathrm{~L} / \mathrm{min}$ through the nasal cannulae or nasal mask (see Table 1). The pressures reached were slightly lower in the neonatal intubation manikin, and there were larger variations among the different types of interface (see Table 2). The pressures achieved in 


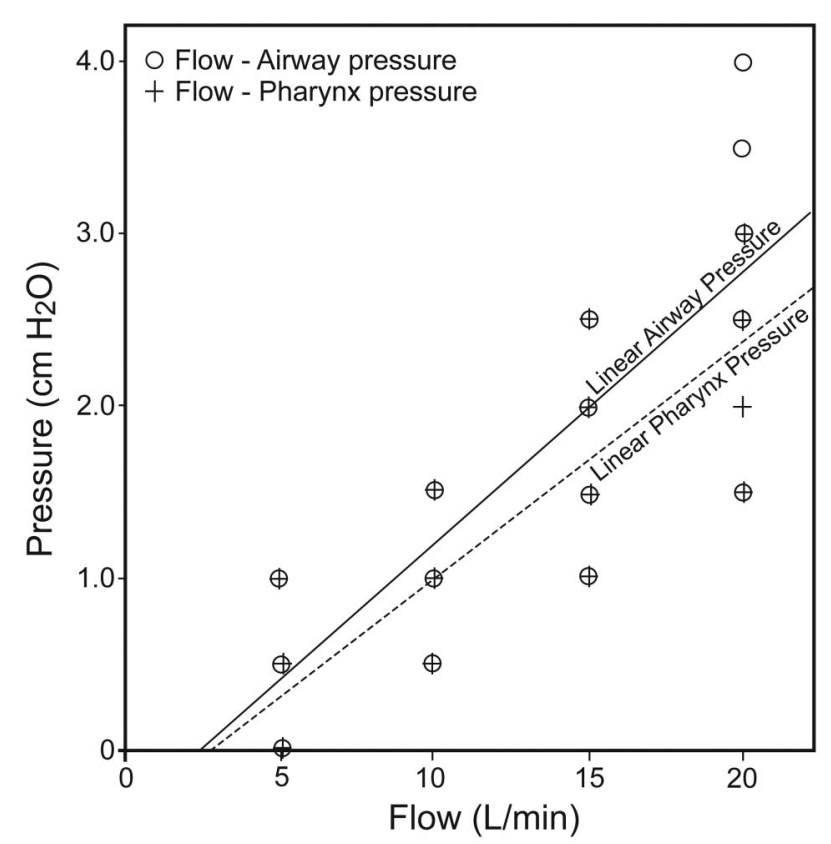

Fig. 2. Scatter plot of pressures measured, with the manikin mouth closed, in the pharynx and airway of both manikins with several interfaces, applying flows of 5, 10, 15, and $20 \mathrm{~L} / \mathrm{min}$. Linear regression equations are represented.

both pharynx and airway were very close. Linear regression analyses showed similar linear relationships between flow and pressures measured in the pharynx (pressure $=$ $-0.375+0.138 \times$ flow) and in the airway (pressure $=$ $-0.375+0.158 \times$ flow) with the closed mouth condition (see Fig. 2). The maximum pressure reached was $4 \mathrm{~cm} \mathrm{H}_{2} \mathrm{O}$ with a flow of $20 \mathrm{~L} / \mathrm{min}$ via the nasal mask.

\section{Discussion}

To our knowledge our study is the first to analyze the pressures generated by a high-flow system in experimental infant and neonatal models, using different flows and interfaces. The hypotheses in our study were that the continuous positive pressure generated by the high-flow oxygen therapy system was dependent on the flow as long as there was no change in system leakage, and that elevated flow rates in pediatric models of the high-flow oxygen therapy system could produce moderate pressures. Other authors who have studied the administration of CPAP through nasal cannulae using non-respirator-based systems also report that the pressure generated depends on the flow and on the percentage leakage between the interface and the nares. ${ }^{14,16-20}$ CPAP is particularly variable when systems are used that submerge the expiratory limb under a water seal, producing bubbles..$^{21}$ There are numerous methods for achieving a continuous positive pressure in the airway. The circuit used in this study lacks an expiratory limb, and the pressure is produced through the effect of the administration of a gas into a cavity at high speed, giving rise to resistance to expiratory flow and generating a virtual valve effect.

In 2 studies in premature and full-term neonates using lower maximum flow rates than in our study, pressures were observed between $4.8 \mathrm{~cm} \mathrm{H}_{2} \mathrm{O}$ (flow rate $4 \mathrm{~L} / \mathrm{min}$, $0.2 \mathrm{~cm}$ cannulae) ${ }^{16}$ and $9.8 \mathrm{~cm} \mathrm{H}_{2} \mathrm{O}$ (flow rate $2.5 \mathrm{~L} / \mathrm{min}$, $0.3 \mathrm{~cm}$ cannulae), ${ }^{15}$ measured in the esophagus and oral cavity. In another study that also used an experimental model, maximum pressures of $4.5 \mathrm{~cm} \mathrm{H}_{2} \mathrm{O}$ were observed with flows of $8 \mathrm{~L} / \mathrm{min}$ and cannulae with an external diameter of $0.2 \mathrm{~cm} .{ }^{16}$

Studies performed in adults have reported maximum pressures in the esophagus of $2.9 \mathrm{~cm} \mathrm{H}_{2} \mathrm{O}$ with $20 \mathrm{~L} / \mathrm{min}$, $5.3 \mathrm{~cm} \mathrm{H}_{2} \mathrm{O}$ with $50 \mathrm{~L} / \mathrm{min}$, and $7.4 \mathrm{~cm} \mathrm{H}_{2} \mathrm{O}$ with $60 \mathrm{~L} /$ min. ${ }^{12,22}$ Nasopharyngeal airway pressures of $1.93 \pm 1.25$, $2.58 \pm 1.54$, and $3.31 \pm 1.05 \mathrm{~cm} \mathrm{H}_{2} \mathrm{O}$ with the mouth closed were generated at 30,40 , and $50 \mathrm{~L} / \mathrm{min}$, respectively. ${ }^{23}$

The maximum pressures found in our study were between 3 and $4 \mathrm{~cm} \mathrm{H}_{2} \mathrm{O}$. The pressures reached were similar with nasal cannulae and with the nasal mask. Nasal and oronasal masks are sometimes poorly tolerated by infants, as they need to be held on tightly; can make communication, oral feeding, and oral hygiene difficult; and can give rise to ulceration in the areas of contact, despite nursing care. Nasal cannulae are generally better tolerated than nasal masks and can be used for the administration of low-pressure CPAP. However, the efficacy may be lower. ${ }^{24}$ More recently, nasal prongs are being used as an interface for the administration of high-flow oxygen therapy in adults (Optiflow, Fisher \& Paykel, New Zealand), and a number of studies provide evidence of their efficacy for administering high and stable oxygen concentrations and a lowmoderate continuous positive pressure with high flow rates, with good tolerability. ${ }^{12,20,22,25}$ In our center we use these prongs to administer noninvasive ventilation in children, with good results. ${ }^{26}$

The mechanism through which high-flow oxygen therapy acts is not fully understood. ${ }^{27}$ It is not known whether the effect is due purely to the changes in lung mechanics induced by the pressure generated by the system, or whether the administration of gas at a temperature similar to body temperature and with a high level of humidity may also have a beneficial role. The administration of warmed, humidified gas has been associated with an increase in ciliary activity, decreased viscosity of secretions, and changes in the epithelial mucosa. In addition, it may prevent the onset of cold-induced bronchospasm. ${ }^{28}$ Furthermore, contact of the respiratory mucosa with the warmed, humidified gas could favor a reduction in edema, which would be a beneficial effect in post-extubation upper respiratory tract insufficiency and has been reported in some studies. ${ }^{6,8,11,27,29}$ A number of studies have demonstrated that the adminis- 


\section{High-Flow Oxygen Therapy: Pressure Analysis in a Pediatric Airway Model}

tration of high-flow oxygen produces a higher concentration of oxygen in the pharynx and better oxygenation of the patient, $22,27,29$ as the upper airways act as a reservoir during expiration, storing the oxygen and contributing to an increase in the concentration in the following inspiration. The utility of high-flow oxygen therapy has also been demonstrated in the management of apnea..$^{7,11}$

As other authors have already indicated, it is important to investigate thoroughly the safety of using these systems. ${ }^{14,16,21}$ As the circuit is not fitted with a high-pressure valve, if the cannulae become sealed into the nasal fossae in a way that blocks any escape, very high pressures could theoretically develop if the patient's mouth is closed. This could be avoided by including a system in the circuit that avoids excessive pressure, by measuring the pressure generated, and by choosing an appropriate interface. ${ }^{14}$ In our study, the pressures reached in the circuit were very high, particularly on using interfaces with a small diameter and high flows, although the pressures reached in the airway were always low.

Our study has certain limitations. It was performed on 2 experimental models of the airway that simulate the anatomy of neonates and infants, but they do not reproduce the physiological responses of the airway, nor do they enable us to observe the interaction with the patient's respiration. The model measures pressures generated in a theoretical trachea and esophagus, with the assumption that the resistance to air flow at the opening of both is similar to in vivo physiology. The experimental design also does not account for active inspiration and expiration, functioning vocal cords that actively open and close, temperature, presence of mucus, compliance of structures, air leaks, as well as the dynamic movements of an infant or neonate that occur on a routine basis. The compliance of the airway and esophagus in the experimental model does not correlate to in vivo physiology. Areas that this model does not take into account are airway pressures actually generated or transduced to the most distal bronchioles. However, we have been able to define better the relationship between flow and the pressure generated, omitting some of the factors that have greatest influence, such as respiration, patient posture, and, above all, system leakage.

\section{Conclusions}

We conclude that high-flow oxygen therapy systems in an experimental pediatric model produced a low-level CPAP, even with the use of very high flow rates. This would suggest that not only positive pressures, but also the administration of a high rate of flow of warmed, humidified air is responsible in part for the benefits achieved by these systems. The fact that high-flow oxygen therapy systems continue to be effective despite leakage through the mouth supports this hypothesis.

\section{ACKNOWLEDGMENTS}

We thank all of the nurses of the Pediatric Intensive Care Unit of the Gregorio Marañón General University Hospital, who assisted with our work.

\section{REFERENCES}

1. Cheifetz IM. Invasive and noninvasive pediatric mechanical ventilation. Respir Care 2003;48(4):442-458.

2. Medina A, Prieto S, Los Arcos M, Rey C, Concha A, Menéndez S, et al. Non-invasive ventilation in a paediatric intensive care unit. An Pediatr (Barc) 2005;62(1):13-19.

3. Fauroux B, Lavis JF, Nicot F, Picard A, Boelle PY, Clément A, et al. Facial side effects during non-invasive positive pressure ventilation in children. Intensive Care Med 2005;31(7):965-969.

4. do Nascimento RM, Ferreira AL, Coutinho AC, Santos Veríssimo RC. The frequency of nasal injury in newborns due to the use of continuous positive airway pressure with prongs. Rev Latino Am Enfermagem 2009;17(4):489-494.

5. Waugh JB, Granger WM. An evaluation of two new devices for nasal high-flow gas therapy. Respir Care 2004;49(8):902-906.

6. Saslow JG, Aghai ZH, Nakhla TA, Hart JJ, Lawrysh R, Stahl GE, et al. Work of breathing using high-flow nasal cannula in preterm infants J Perinatol 2006;26(8):476-480.

7. Kubicka Z, Limauro J, Damall R. Heated, humidified high-flow nasal cannula therapy: yet another way to deliver continuous positive airway pressure? Pediatrics 2008;121(1):82-88.

8. Urbano J, Mencía S, Cidoncha E, López-Herce J, Santiago MJ, Carrillo A. Experience with high-flow nasal cannula oxygen therapy in children. An Pediatr (Barc) 2008;68(1):4-8.

9. Spentzas T, Minarik M, Patters AB, Vinson B, Stidham G. Children with respiratory distress treated with high-flow nasal cannula. J Intensive Care Med 2009;24(5):323-328.

10. McKiernan C, Chua LC, Visintainer PF, Allen H. High flow nasal cannulae therapy in infants with bronchiolitis. J Pediatr 2010;156(4): 634-638.

11. Groves N, Tobin A. High flow nasal oxygen generates positive airway pressure in adult volunteers. Aust Crit Care 2007;20(4):126131.

12. Finer NN. Nasal cannula use in the preterm infant: oxygen or pressure? Pediatrics 2005;116(5):1216-1217.

13. Lampland AL, Plumm B, Meyers PA, Worwa CT, Mammel MC. Observational study of Humidified high-flow nasal cannula compared with nasal continuous positive airway pressure. J Pediatr 2009; 154(2):177-182.

14. Locke RG, Wolfson MR, Shaffer TH, Rubenstein D, Greenspan JS. Inadvertent administration of positive end-expiratory pressure during nasal cannula flow. Pediatrics 1993;91(1):135-138.

15. Sreenan C, Lemke RP, Hudson-Mason A, Osiovich H. High-flow nasal cannulae in the management of apnea of prematurity: a comparison with conventional nasal continuous positive airway pressure. Pediatrics 2001;107(5):1081-1083.

16. Kahn DJ, Courtney SE, Steele AM, Habib RH. Unpredictability of delivered bubble nasal continuous positive airway pressure: role of bias flow magnitude and nares-prong air leaks. Pediatr Res 2007; 62(3):343-347.

17. Kahn DJ, Habib RH, Courtney SE. Effects of flow amplitudes on intraprong pressures during bubble versus ventilator-generated nasal continuous positive airway pressure in premature infants. Pediatrics 2008;122(5):1009-1013.

18. Hasan RA, Habib RH. Effects of flow rate and airleak at the nares and mouth opening on positive distending pressure delivery using 


\section{High-Flow Oxygen Therapy: Pressure Analysis in a Pediatric Airway Model}

commercially available high-flow nasal cannula systems: a lung model study. Pediatr Crit Care Med 2011;12(1):e29-33.

19. Frizzola M, Miller TL, Rodriguez ME, Zhu Y, Rojas J, Hesek A, et al. High-flow nasal cannula: impact on oxygenation and ventilation in an acute lung injury model. Pediatr Pulmonol 2011;46(1):6774.

20. Parke R, McGuinness S, Eccleston M. Nasal high-flow therapy delivers low level positive airway pressure. Br J Anaesth 2009;103(6): 886-890.

21. Williams AB, Ritchie JE, Gerard C. Evaluation of a high flow nasal oxygenation system: gas analysis and pharyngeal pressures. Intensive Care Med 2006;32(1 Suppl):S219.

22. De Paoli AG, Davis PG, Faber B, Morley CJ. Devices and pressure sources for administration of nasal continuous positive airway pressure (nCPAP) in preterm neonates. Cochrane Database Syst Rev 2008 23;(1):CD002977.

23. Parke RL, Eccleston ML, McGuinness SP. The effects of flow on airway pressure during nasal high-flow oxygen therapy. Respir Care 2011;56(8):1151-1155
24. Moloney E, O'Sullivan S, Hogan T, Poulter LW, Burke CM. Airway de-hydratation : a therapeutic target in asthma? Chest 2002;121(6): 1806-1811.

25. Byerly FL, Haithcock JA, Buchanan IB, Short KA, Cairns BA. Use of high flow nasal cannula on a pediatric burn patient with inhalation injury and post-extubation stridor. Burns 2006;32(1):121-125.

26. Figueruelo AG, Villaescusa JU, Prieto MB, García MJ, Bartolomé SM, Cid JL. [Use of high-flow nasal cannula for non-invasive ventilation in children.] An Pediatr (Barc) 2011;75(3):182-187. Article in Spanish.

27. Dysart K, Miller TL, Wolfson MR, Shaffer TH. Research in high flow therapy: mechanisms of action. Respir Med 2009;103(10):1400-1405.

28. Kuluz JW, Mc Laughlin GE, Gelman B, Cantwell GP, Thomas J, Mahon T, et al. The fraction of inspired oxygen in infants receiving oxygen via nasal cannula often exceeds safe levels. Respir Care 2001;46(9):897-901.

29. Wettsein R, Shelledy DC, Peters JI. Delivered oxygen concentrations using low-flow and high flow nasal cannulas. Respir Care 2005; 50(5):604-609.

This article is approved for Continuing Respiratory Care Education credit. For information and to obtain your CRCE

(free to AARC members) visit www.RCJournal.com 